\title{
Morphometry of the Cranial Base in Subjects with Class III Malocclusion
}

\author{
G.D. Singh ${ }^{1 *}$, J.A. McNamara, Jr. ${ }^{2}$, and S. Lozanoff ${ }^{3}$
}

${ }^{1}$ Department of Dental Surgery \& Periodontology, Dundee Dental Hospital \& School, University of Dundee, Park Place, Dundee DD1 4HR, Scotland, UK; ${ }^{2}$ Department of Orthodontics \& Pediatric Dentistry, School of Dentistry, Center for Human Growth and Development, University of Michigan, Ann Arbor, Michigan 48109-1078, USA; and ${ }^{3}$ Departments of Anatomy and Reproductive Biology and of Surgery, John A. Burns School of Medicine, University of Hawaii, Honolulu, Hawaii 96882; *to whom correspondence and reprint requests should be addressed

\begin{abstract}
The significance of the cranial base in the development of Class III malocclusion remains uncertain. The purpose of this study was to determine whether the form of the cranial base differs between prepubertal Class I and Class III subjects. Lateral cephalographs of 73 children of European-American descent aged between 5 and 11 years with Class III malocclusion were compared with those of their counterparts with a normal, Class I molar occlusion. The cephalographs were traced, checked, and subdivided into seven age- and sex-matched groups. Average geometries, scaled to an equivalent size, were generated based on 13 craniofacial landmarks by means of Procrustes analysis, and these configurations were statistically tested for equivalence. Bivariate and multivariate analyses utilizing 5 linear and angular measurements were undertaken to corroborate the Procrustes analysis. Graphical analysis, utilizing thin-plate spline and finite element methods, was performed for localization of differences in cranial base morphology. Results indicated that cranial base morphology differed statistically for all age-wise comparisons. Graphical analysis revealed that the greatest differences in morphology occurred in the posterior cranial base region, which generally consisted of horizontal compression, vertical expansion, and size contraction. The sphenoidal region displayed expansion, while the anterior regions showed shearing and local increases in size. It is concluded that the shape of the cranial base differs in subjects with Class III malocclusion compared with the normal Class I configuration, due in part to deficient orthocephalization, or failure of the cranial base to flatten during development.
\end{abstract}

Key words: Class III, cranial base, morphometry, orthocephalization.

Received July 24, 1995; Accepted August 14, 1996

\section{Introduction}

Class III malocclusions result from morphological disharmony between the maxilla and mandible. This group of malocclusions is characterized generally by several developmental and craniofacial features, including an acute mandibular plane angle, obtuse gonial angle, and an overdeveloped mandible/underdeveloped maxilla (Jacobson et al., 1974; Ellis and McNamara, 1984; Sato, 1994). Although Class III malocclusions occur much less frequently than Class II malocclusions (Haynes, 1970; Foster and Day, 1974), they frequently are associated with craniofacial syndromes and require orthodontic intervention for the correction of functional deficiencies in mastication, respiration, and/or phonation. Therefore, the etiology and expression of Class III malocclusion must be understood before it can be clinically corrected.

Maxillary retrognathia, without mandibular prognathism, has been reported to occur in between 20 and $30 \%$ of adult patients with Class III malocclusions (Sanborn, 1955; Dietrich, 1970; Jacobson et al., 1974; Ellis and McNamara, 1984). The cranial base is a likely anatomical candidate to be involved in Class III malocclusions, since it forms the central core of the cranium, providing a major support structure on which the midface develops. Similarly, the cranial base is abnormally short with a deficient posterior region in an experimental midfacially-retrognathic mouse model (Lozanoff et al., 1994; Ma and Lozanoff, 1996). While some authors report that a short cranial base is a major morphological feature characteristic of a Class III craniofacial configuration (Stapf, 1948; Hopkin et al., 1968; Kerr and Adams, 1988), others suggest that a Class III cranial base morphology does not differ from that seen in subjects with a normal Class I profile (Anderson and Popovich, 1983). A possible explanation for these contradictory results may be that the cranial base is usually represented by a limited number of anatomical landmarks which may not be sufficient for accurate characterization of its contribution to the Class III configuration. Also, most studies do not account for size differences between individuals which may confound results, as noted by Battagel $(1993,1994)$. The purpose of this study was to test the hypothesis that cranial 
base morphometry differs between Class I and Class III subjects. If significant differences between cranial base morphologies are found, anatomical alterations will be localized graphically. This study capitalizes on newer morphometric techniques which normalize geometric areas, thus eliminating the confounding effects introduced by size differences between individuals.

\section{Materials and methods}

\section{Sample}

The sample used in this analysis was derived from a total of 142 children of European-American descent between the ages of 5 and 11 years. The use of archival radiographs conformed to institutional standards at the University of Michigan (USA), since human subjects had participated after providing informed consent to a protocol that had been reviewed and approved by an appropriate institutional board. A total of 73 subjects with Class III molar occlusion (Guyer et al., 1986) was compared with 69 children with a normal, Class I molar relationship over seven age intervals. The total sample included an approximately equal number of male and female individuals, with negative history of airway problems and no obvious vertical skeletal discrepancies. The chronological age was assumed to match developmental age in this study, since carpal radiographs were unavailable. Therefore, the total sample consisted of seven age-matched $(5,6$, $7,8,9,10,11$ years) and gender-matched groups for each occlusal type (Class I, Class III).

Lateral cephalographs were used in this analysis. The magnification of each film was standardized to an $8 \%$ enlargement factor. It was presumed that all radiographs were taken from patients exhibiting left-right symmetry and that the central $x$-ray passed along the trans-meatal axis while the teeth were in occlusion. Each lateral cephalograph was traced on frosted acetate film (0.03" thick) and checked by one investigator (GDS). To increase the reliability of the landmarks selected, we taped cephalographs to a light box of uniform brightness in a darkened room and used a cross-wires cursor to achieve digitization of landmarks. Thirteen points on the cranial base and midface were identified and digitized (Fig. 1, Table 1) by means of appropriate software and a digitizing table (Numonics Inc., Montgomeryville, PA). The rationale of selection was that preference was given to landmarks that encompassed cranial developmental sites and were located in the mid-sagittal plane where possible (Varjanne and Koski, 1982). These landmarks (Fig. 1, Table 1) showed a discrepancy of $<1 \%$ on duplicate digitization and were deemed to be reliably identified.

\section{Statistical analysis}

Procrustes analysis was used for determination of whether cranial base landmark configurations differed between occlusal types at each age interval. A routine was written in " $\mathrm{C}$ " and implemented on an Amiga 3000. An average 13-node geometry for each age group was determined by Generalized Orthogonal Procrustes analysis (Gower, 1975; Rohlf and Slice, 1990). Following this method, every object's coordinates were translated, rotated, and scaled iteratively until the least-squares fit of all configurations was no longer improved. Therefore, all configurations were scaled to an equivalent size and registered with respect to one another. Each Class I group mean geometry was compared statistically with the age-matched Class III group 
Table 1. Definitions of landmarks and variables used in this study

\begin{tabular}{|c|c|c|}
\hline Abbreviations & \multicolumn{2}{|c|}{ Cranial Landmarks } \\
\hline Ar & \multicolumn{2}{|c|}{$\begin{array}{l}\text { Articulare (intersection of the condyle and the } \\
\text { posterior cranial base) }\end{array}$} \\
\hline $\mathrm{Ba}$ & \multicolumn{2}{|c|}{$\begin{array}{l}\text { Basion (lowest point on the anterior border of } \\
\text { foramen magnum) }\end{array}$} \\
\hline Bo & \multicolumn{2}{|c|}{$\begin{array}{l}\text { Bolton point (highest point behind the occipital } \\
\text { condyle) }\end{array}$} \\
\hline Fmn & \multicolumn{2}{|c|}{ Frontonasomaxillary suture } \\
\hline Gl & \multicolumn{2}{|c|}{ Glabella (most prominent point on the frontal bone) } \\
\hline Pc & \multicolumn{2}{|c|}{$\begin{array}{l}\text { Posterior clinoid process (most superior point on the } \\
\text { clinoid process) }\end{array}$} \\
\hline $\mathrm{N}$ & \multicolumn{2}{|c|}{ Nasion (most anterior point on frontonasal suture) } \\
\hline $\mathrm{Nb}$ & \multicolumn{2}{|c|}{ Tip of nasal bone } \\
\hline $\mathrm{Pt}$ & \multicolumn{2}{|c|}{$\begin{array}{l}\text { Rickett's point (posterosuperior point on outline of } \\
\text { pterygomaxillary fissure) }\end{array}$} \\
\hline Ptm & \multicolumn{2}{|c|}{$\begin{array}{l}\text { Pterygo-maxillare (most inferior point on outline of } \\
\text { pterygomaxillary fissure) }\end{array}$} \\
\hline$S$ & \multicolumn{2}{|c|}{ Sella (center of sella turcica) } \\
\hline Se & \multicolumn{2}{|c|}{$\begin{array}{l}\text { Sphenoidale (intersection of the greater wings of the } \\
\text { sphenoid and the anterior cranial base) }\end{array}$} \\
\hline Ts & \multicolumn{2}{|c|}{ Tuberculum sellae (most anterior point of sella turcica) } \\
\hline Cranial Lin & near Variables (mm) & Cranial Angular Variables $\left(^{\circ}\right)$ \\
\hline & S-N & NSBa \\
\hline & S-Ba & NSAr \\
\hline & $\mathrm{N}-\mathrm{Se}$ & NSeS \\
\hline & S-Se & NPcBo \\
\hline & Pc-Bo & GINNb \\
\hline
\end{tabular}

average geometry by an analysis of variance (Gower, 1975; Appendix). In each case, the null hypothesis was that the Class I mean was not significantly different from the Class III average. Residuals and corresponding $F$ values were computed, tabulated, and compared.

A battery of five linear and five angular cranial base measurements was delineated and analyzed by bivariate and multivariate statistical analysis, due to concerns expressed by Lele (1993) regarding the robustness of Procrustes analysis. Linear distances $(\mathrm{mm})$ between coordinates were calculated as well as selected angles $\left({ }^{\circ}\right)$ for each individual. Each variable was tested for normality within each group by Wilks' statistic (BMDP3D). Also, the assumption of equivalence of variance was verified for each linear and angular variable between age-matched groups by Levene's test, and the corresponding means were subsequently compared for equivalence by a $t$ test (BMDP-3D). Following this bivariate analysis, measurements were compared by a multivariate Hotelling's $t$ test (BMDP-3D) so that the results derived from the Procrustes analysis could be corroborated.

\section{Graphical analysis}

To localize differences in cranial base morphologies, we undertook two graphical analyses. The average landmark configuration for each age group generated with the Procrustes analysis was used for this analysis. Thin-plate spline analysis
Table 2. Residuals, F values, and probability of statistical equivalence between average cranial base geometries for Class I and Class III groups between 5 and 11 years of age as determined with the Procrustes analysis

\begin{tabular}{cccl}
\hline Age & $\begin{array}{c}\text { Residual } \\
\left(\times 10^{3}\right)\end{array}$ & F value & $\mathrm{p}<$ \\
\hline 5 & 3.268 & 4.512 & 0.001 \\
6 & 1.749 & 1.756 & 0.010 \\
7 & 1.305 & 1.432 & 0.100 \\
8 & 2.658 & 3.353 & 0.001 \\
9 & 2.222 & 3.795 & 0.001 \\
10 & 1.751 & 1.482 & 0.050 \\
11 & 1.605 & 1.870 & 0.005 \\
\hline
\end{tabular}

was undertaken following Bookstein (1991) and Rohlf (1996). Graphical displays of the total spline comparison (affine and non-affine components combined) at each age interval were calculated. Qualitative analysis was undertaken by the identification of areas of greatest deformation; these alterations were then characterized. Similarly, finite element methodology (FEM) was undertaken following Lozanoff and Diewert (1989). In this case, the Class I average was taken as the initial geometry, and the Class III configuration was the final geometry. Size-change variables were calculated as the product of principal extensions (Lozanoff and Diewert, 1986). These values were calculated for at least 2000 points per geometry and were used for the generation of a color map with a log-linear scale. Areas of greatest or least change were characterized qualitatively, with deformation noted, based on the graphical display. Size-change values were tabulated at the location of the anatomical landmarks. Although statistical comparisons of thinplate spline and FEM form-change variables are possible, no such analysis was undertaken here, since it was considered beyond the scope of this study.

\section{Results}

Residuals from the Procrustes analysis at each age were tabulated and compared by means of an $F$ distribution (Table 2). Statistically significant differences between the landmark configurations occurred at the $p<0.05$ level for all age comparisons except the age 7 group. In this case, the probability of a statistical difference between average landmark configurations was marginal, with $\mathrm{p}<0.10$.

Results of the univariate and multivariate analyses are presented in Tables 3 and 4. Wilks' test indicated that $94 \%$ of the cranial variables displayed a $w>0.9$, indicative of a normal distribution. A further $3.5 \%$ of the variables showed a $w>0.8$ level, and only $1 \%$ of the variables demonstrated a skewed distribution ( $\mathrm{p}<0.05$ ). Therefore, the vast majority of linear measures was taken to be normally distributed. Similarly, Levene's test indicated equivalence of variance for $99 \%$ of the linear and angular variables. Therefore, the assumptions of normality and equivalence of variance were accepted for linear and angular measures, enabling further bivariate and multivariate analyses to be carried out. 
Table 3. Linear and angular measurements for Class I and Class III cranial base morphologies between 5 and 11 years of age with statistically significant differences $(p<0.05)$ in boldface

\begin{tabular}{|c|c|c|c|c|c|c|c|c|c|c|c|c|c|c|}
\hline \multirow{2}{*}{$\frac{\text { Age }}{\text { Variable }}$} & \multicolumn{2}{|c|}{5} & \multicolumn{2}{|c|}{6} & \multicolumn{2}{|c|}{7} & \multicolumn{2}{|c|}{8} & \multicolumn{2}{|c|}{9} & \multicolumn{2}{|c|}{10} & \multicolumn{2}{|c|}{11} \\
\hline & $\begin{array}{c}\text { Class } \\
\text { I }\end{array}$ & $\begin{array}{c}\text { Class } \\
\text { III }\end{array}$ & $\begin{array}{c}\text { Class } \\
\text { I }\end{array}$ & $\begin{array}{c}\text { Class } \\
\text { III }\end{array}$ & $\begin{array}{c}\text { Class } \\
\text { I }\end{array}$ & $\begin{array}{c}\text { Class } \\
\text { III }\end{array}$ & $\begin{array}{c}\text { Class } \\
\text { I }\end{array}$ & $\begin{array}{c}\text { Class } \\
\text { III }\end{array}$ & $\begin{array}{c}\text { Class } \\
\text { I }\end{array}$ & $\begin{array}{c}\text { Class } \\
\text { III }\end{array}$ & $\begin{array}{c}\text { Class } \\
\text { I }\end{array}$ & $\begin{array}{c}\text { Class } \\
\text { III }\end{array}$ & $\begin{array}{c}\text { Class } \\
\text { I }\end{array}$ & $\begin{array}{c}\text { Class } \\
\text { III }\end{array}$ \\
\hline $\mathrm{N}(\mathrm{mm})$ & $\begin{array}{l}70.6 \\
(3.4)^{\mathrm{a}}\end{array}$ & $\begin{array}{l}69.8 \\
(3.2)\end{array}$ & $\begin{array}{l}70.0 \\
(2.3)\end{array}$ & $\begin{array}{l}67.4 \\
(2.5)\end{array}$ & $\begin{array}{l}71.3 \\
(1.2)\end{array}$ & $\begin{array}{l}69.8 \\
(3.6)\end{array}$ & $\begin{array}{c}72.9 \\
(2.7)\end{array}$ & $\begin{array}{l}68.3 \\
(2.9)\end{array}$ & $\begin{array}{c}74.1 \\
(2.6)\end{array}$ & $\begin{array}{l}69.6 \\
(2.9)\end{array}$ & $\begin{array}{c}72.8 \\
(2.2)\end{array}$ & $\begin{array}{c}70.1 \\
(3.2)\end{array}$ & $\begin{array}{c}74.1 \\
(3.7)\end{array}$ & $\begin{array}{c}72.8 \\
(4.1)\end{array}$ \\
\hline NSe (mm) & $\begin{array}{l}43.7 \\
(1.5)\end{array}$ & $\begin{array}{l}41.9 \\
(2.6)\end{array}$ & $\begin{array}{l}42.3 \\
(2.6)\end{array}$ & $\begin{array}{l}42.9 \\
(3.2)\end{array}$ & $\begin{array}{l}44.2 \\
(2.0)\end{array}$ & $\begin{array}{l}43.8 \\
(3.7)\end{array}$ & $\begin{array}{l}46.7 \\
(2.9)\end{array}$ & $\begin{array}{l}42.8 \\
(3.3)\end{array}$ & $\begin{array}{l}45.9 \\
(3.0)\end{array}$ & $\begin{array}{l}43.5 \\
(3.2)\end{array}$ & $\begin{array}{l}44.6 \\
(1.6)\end{array}$ & $\begin{array}{l}43.8 \\
(3.5)\end{array}$ & $\begin{array}{l}48.7 \\
(4.2)\end{array}$ & $\begin{array}{l}45.4 \\
(3.6)\end{array}$ \\
\hline $\mathrm{SSe}(\mathrm{mm})$ & $\begin{array}{l}27.0 \\
(3.4)\end{array}$ & $\begin{array}{l}25.9 \\
(2.7)\end{array}$ & $\begin{array}{l}27.9 \\
(1.7)\end{array}$ & $\begin{array}{l}25.0 \\
(2.2)\end{array}$ & $\begin{array}{l}27.3 \\
(1.1)\end{array}$ & $\begin{array}{l}26.2 \\
(2.6)\end{array}$ & $\begin{array}{l}26.6 \\
(1.4)\end{array}$ & $\begin{array}{c}25.5 \\
(2.8)\end{array}$ & $\begin{array}{l}28.3 \\
(3.0)\end{array}$ & $\begin{array}{c}26.2 \\
(2.1)\end{array}$ & $\begin{array}{l}25.4 \\
(8.4)\end{array}$ & $\begin{array}{l}26.5 \\
(4.0)\end{array}$ & $\begin{array}{l}25.5 \\
(2.9)\end{array}$ & $\begin{array}{l}27.5 \\
(2.0)\end{array}$ \\
\hline $\mathrm{SBa}(\mathrm{mm})$ & $\begin{array}{l}42.2 \\
(2.9)\end{array}$ & $\begin{array}{l}41.1 \\
(1.8)\end{array}$ & $\begin{array}{l}42.4 \\
(2.4)\end{array}$ & $\begin{array}{l}40.6 \\
(2.9)\end{array}$ & $\begin{array}{l}42.4 \\
(3.5)\end{array}$ & $\begin{array}{l}43.6 \\
(2.9)\end{array}$ & $\begin{array}{l}45.4 \\
(2.7)\end{array}$ & $\begin{array}{l}44.3 \\
(2.6)\end{array}$ & $\begin{array}{l}46.8 \\
(3.5)\end{array}$ & $\begin{array}{l}43.1 \\
(3.1)\end{array}$ & $\begin{array}{l}46.8 \\
(3.3)\end{array}$ & $\begin{array}{l}45.2 \\
(1.7)\end{array}$ & $\begin{array}{l}47.6 \\
(3.7)\end{array}$ & $\begin{array}{l}45.6 \\
(2.4)\end{array}$ \\
\hline $\mathrm{PcBo}(\mathrm{mm})$ & $\begin{array}{c}55.4 \\
(3.0)\end{array}$ & $\begin{array}{l}46.7 \\
(2.8)\end{array}$ & $\begin{array}{l}52.1 \\
(3.8)\end{array}$ & $\begin{array}{l}44.1 \\
(4.9)\end{array}$ & $\begin{array}{l}52.9 \\
(4.5)\end{array}$ & $\begin{array}{l}47.3 \\
(6.2)\end{array}$ & $\begin{array}{l}58.9 \\
(4.10)\end{array}$ & $\begin{array}{c}48.1 \\
(4.2)\end{array}$ & $\begin{array}{l}59.6 \\
(5.2)\end{array}$ & $\begin{array}{l}48.1 \\
(5.0)\end{array}$ & $\begin{array}{l}59.6 \\
(5.4)\end{array}$ & $\begin{array}{l}50.1 \\
(5.3)\end{array}$ & $\begin{array}{c}59.6 \\
(5.3)\end{array}$ & $\begin{array}{l}53.6 \\
(4.9)\end{array}$ \\
\hline $\operatorname{GINNb}\left({ }^{\circ}\right)$ & $\begin{array}{r}135.5 \\
(5.1)\end{array}$ & $\begin{array}{c}136.0 \\
(8.20)\end{array}$ & $\begin{array}{r}127.1 \\
(5.7)\end{array}$ & $\begin{array}{r}141.1 \\
(5.2)\end{array}$ & $\begin{array}{c}136.9 \\
(8.5)\end{array}$ & $\begin{array}{r}138.3 \\
(5.2)\end{array}$ & $\begin{array}{r}137.5 \\
(6.7)\end{array}$ & $\begin{array}{r}138.1 \\
(7.5)\end{array}$ & $\begin{array}{r}133.2 \\
(5.8)\end{array}$ & $\begin{array}{r}139.4 \\
(4.6)\end{array}$ & $\begin{array}{c}136.2 \\
(6.1)\end{array}$ & $\begin{array}{r}136.1 \\
(4.9)\end{array}$ & $\begin{array}{r}131.9 \\
(6.5)\end{array}$ & $\begin{array}{r}139.8 \\
(4.6)\end{array}$ \\
\hline $\operatorname{NSeS}\left({ }^{\circ}\right)$ & $\begin{array}{c}176.3 \\
(3.6)\end{array}$ & $\begin{array}{r}175.3 \\
(4.0)\end{array}$ & $\begin{array}{c}171.9 \\
(5.9)\end{array}$ & $\begin{array}{r}176.3 \\
(1.7)\end{array}$ & $\begin{array}{r}174.3 \\
(5.0)\end{array}$ & $\begin{array}{c}173.3 \\
(2.4)\end{array}$ & $\begin{array}{c}169.9 \\
(7.1)\end{array}$ & $\begin{array}{r}173.7 \\
(3.3)\end{array}$ & $\begin{array}{c}175.2 \\
(3.0)\end{array}$ & $\begin{array}{c}176.0 \\
(2.9)\end{array}$ & $\begin{array}{c}175.4 \\
(2.5)\end{array}$ & $\begin{array}{r}173.1 \\
(4.5)\end{array}$ & $\begin{array}{r}175.9 \\
(3.3)\end{array}$ & $\begin{array}{r}174.6 \\
(3.6)\end{array}$ \\
\hline $\mathrm{NSBa}\left({ }^{\circ}\right)$ & $\begin{array}{c}128.3 \\
(4.8)\end{array}$ & $\begin{array}{r}122.6 \\
(6.6)\end{array}$ & $\begin{array}{c}127.0 \\
(3.6)\end{array}$ & $\begin{array}{c}129.9 \\
(4.3)\end{array}$ & $\begin{array}{c}128.1 \\
(3.6)\end{array}$ & $\begin{array}{c}128.1 \\
(4.10)\end{array}$ & $\begin{array}{r}134.3 \\
(2.0)\end{array}$ & $\begin{array}{c}125.9 \\
(2.9)\end{array}$ & $\begin{array}{r}131.2 \\
(4.4)\end{array}$ & $\begin{array}{r}126.9 \\
(4.6)\end{array}$ & $\begin{array}{r}129.4 \\
(5.4)\end{array}$ & $\begin{array}{r}126.7 \\
(3.6)\end{array}$ & $\begin{array}{r}128.4 \\
(3.0)\end{array}$ & $\begin{array}{c}126.2 \\
(5.5)\end{array}$ \\
\hline $\operatorname{NSAr}\left({ }^{\circ}\right)$ & $\begin{array}{c}120.2 \\
(6.2)\end{array}$ & $\begin{array}{c}116.9 \\
(6.2)\end{array}$ & $\begin{array}{r}121.7 \\
(5.4)\end{array}$ & $\begin{array}{r}121.8 \\
(1.7)\end{array}$ & $\begin{array}{c}122.3 \\
(3.8)\end{array}$ & $\begin{array}{r}121.6 \\
(3.5)\end{array}$ & $\begin{array}{r}126.9 \\
(4.8)\end{array}$ & $\begin{array}{c}120.3 \\
(2.5)\end{array}$ & $\begin{array}{c}124.9 \\
(5.5)\end{array}$ & $\begin{array}{c}121.1 \\
(5.6)\end{array}$ & $\begin{array}{c}124.7 \\
(6.3)\end{array}$ & $\begin{array}{r}121.1 \\
(4.1)\end{array}$ & $\begin{array}{c}123.2 \\
(5.3)\end{array}$ & $\begin{array}{c}120.4 \\
(5.1)\end{array}$ \\
\hline $\mathrm{NPcBo}\left({ }^{\circ}\right)$ & $\begin{array}{r}136.9 \\
(4.6)\end{array}$ & $\begin{array}{r}123.8 \\
(7.0)\end{array}$ & $\begin{array}{r}131.9 \\
(4.7)\end{array}$ & $\begin{array}{c}132.9 \\
(4.3)\end{array}$ & $\begin{array}{r}133.0 \\
(6.8)\end{array}$ & $\begin{array}{c}129.3 \\
(5.50)\end{array}$ & $\begin{array}{r}138.7 \\
(4.9)\end{array}$ & $\begin{array}{r}126.7 \\
(2.2)\end{array}$ & $\begin{array}{r}137.7 \\
(5.2)\end{array}$ & $\begin{array}{r}129.1 \\
(5.6)\end{array}$ & $\begin{array}{c}136.2 \\
(2.9)\end{array}$ & $\begin{array}{r}129.8 \\
(5.9)\end{array}$ & $\begin{array}{r}135.8 \\
(4.4)\end{array}$ & $\begin{array}{r}127.5 \\
(6.4)\end{array}$ \\
\hline
\end{tabular}

a Standard deviations.

For the anterior cranial base, the length S-N differed statistically between normal and Class III cases only at ages 8 and 9 years. For its subcomponents (S-Se and N-Se), only $\mathrm{N}$-Se differed at age 8 years. No differences in anterior base angulation, depicted by the angle NSeS, were found. However, the frontonasal angle (GlNNb) appeared to be more obtuse in nearly all Class III groups, although it reached statistical significance in only three of the seven age groups tested (ages 6, 9, and 11 years).

For the posterior cranial base, even though the length SBa did not differ statistically between normal and Class III groups at any age, differences were found for all age groups for the length Pc-Bo, which was significantly shorter in all Class III cases. This decreased posterior cranial base length was augmented by a decreased cranial base angle (NPcBo) that was significantly smaller in Class III age groups at 5, 8 , 910 , and 11 years. Although the saddle angle (NSBa) appeared to be more acute in Class III groups, it failed to reach statistical significance in most age groups $(6,7,10$, and 11 years). The angle NSAr followed the same trend, with marginal statistical difference occurring at 8 years of age.

Hotelling's tests confirmed that statistically significant differences existed between normal and Class III cranial bases for both linear and angular measures. At ages 5, 8, and 9 years, statistically significant differences were found for both linear and angular variables. For ages 6, 7, 10, and 11 years, statistically significant differences existed for either linear variables or for the angular measures. Therefore, all age groups tested displayed statistically significant differences for cranial base morphology in either the linear or the angular measures, if not both, corroborating the results achieved by our Procrustes analysis.

Thin-plate spline analysis provided graphical displays comparing the Class I configuration with that of the Class III for each of the seven age intervals (Fig. 2). For the 5-year-old group, the total spline indicated compression in the horizontal axis in the region of the posterior cranial base, affecting Bolton point and basion (Fig. 2A). However, some vertical expansion, particularly in the sphenoidal complex, and downward

Table 4. Hotelling's $\mathrm{T}^{2}$ scores and values of statistical significance for linear and angular measurements of Class I and Class III cranial base morphologies between 5 and 11 years of age

\begin{tabular}{lccrc}
\hline & \multicolumn{2}{c}{ Linear Measurements } & \multicolumn{2}{c}{ Angular Measurements } \\
Age & Hotelling's T & $\mathrm{p}<$ & Hotelling's T $^{2}$ & $\mathrm{p}<$ \\
\hline 5 & 88.15 & 0.0001 & 42.46 & 0.0031 \\
6 & 21.06 & 0.0939 & 31.06 & 0.0373 \\
7 & 32.36 & 0.0148 & 5.64 & 0.5558 \\
8 & 96.89 & 0.0001 & 206.04 & 0.0001 \\
9 & 46.34 & 0.0001 & 28.67 & 0.0049 \\
10 & 21.75 & 0.0374 & 8.91 & 0.3000 \\
11 & 10.71 & 0.1211 & 30.09 & 0.0123 \\
\hline
\end{tabular}




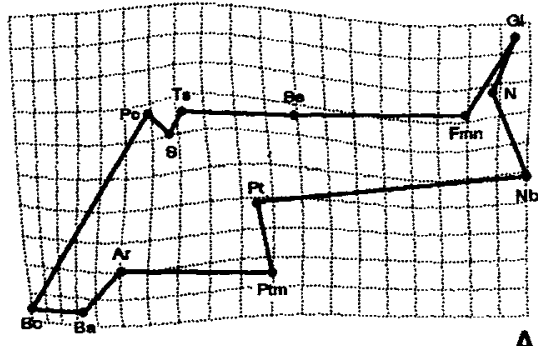

A
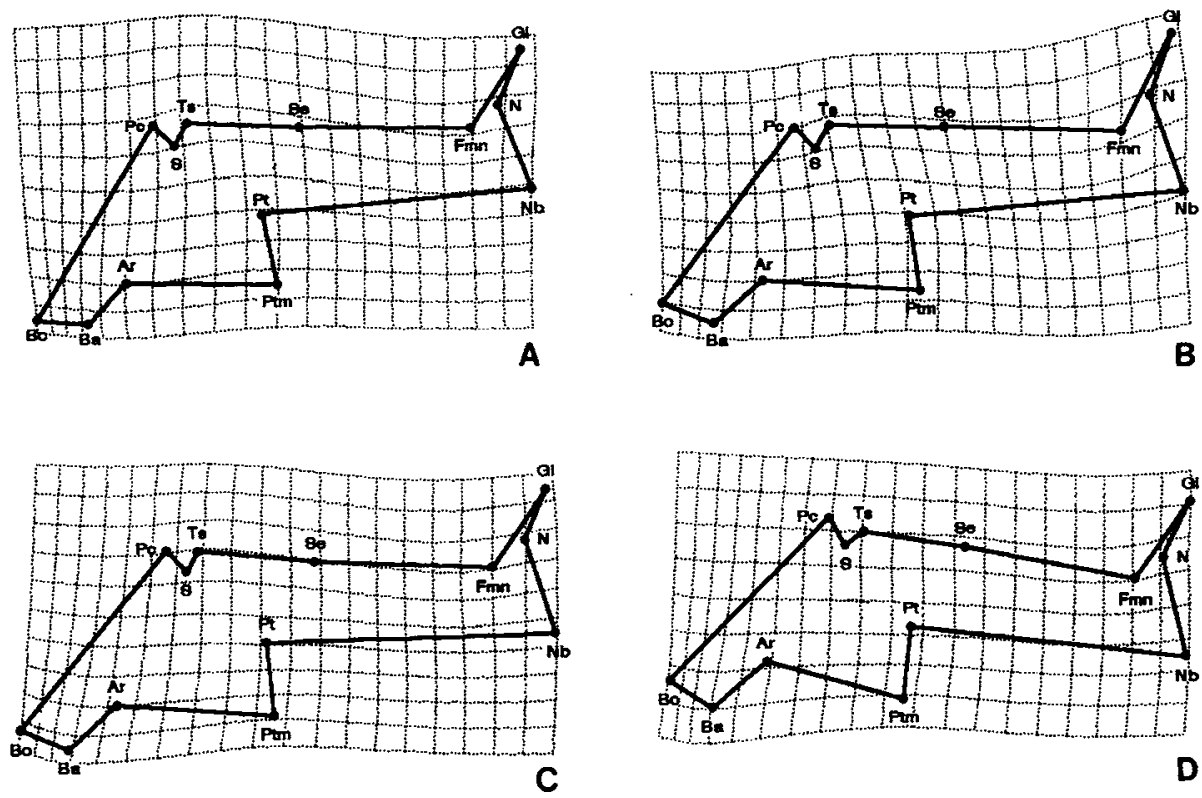

D
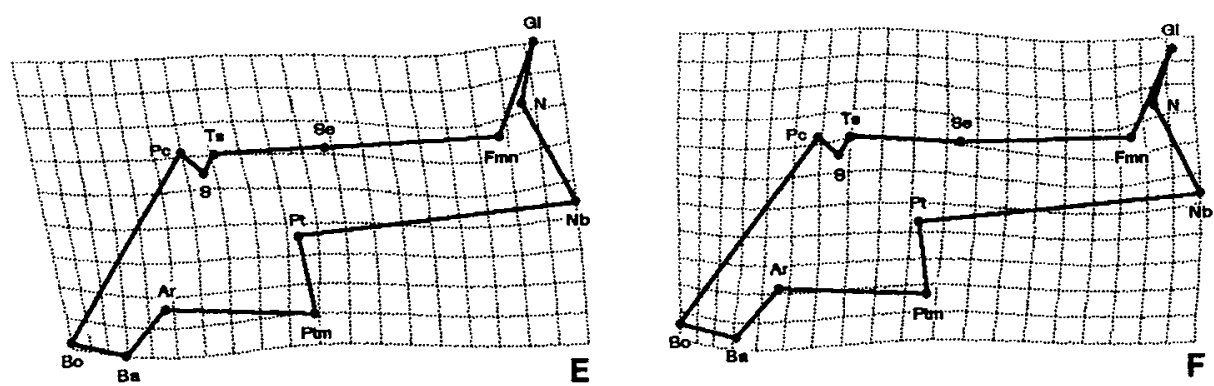

downward deformation (Fig. 2C). For the 8-year-old comparison, the total spline indicated a horizontal compression and a downward displacement of the posterior region of the cranial base, most evident between Bolton point and basion (Fig. 2D). While the mid-cranial region showed a mild forward expansion, an inferior deformation of the anterior cranial base was also present (Fig. 2D). A marked forward compression of the posterior cranial base, particularly at Bolton point and basion, was seen for the 9-year-old comparison, while the midcranial regions showed a mild forward expansion as well as an inferior deformation of the anterior cranial base at the frontonasomaxillary suture (Fig. 2E). A forward compression of the posterior region of the cranial base was present for the 10-yearold comparison, as were a large upward expansion for the midcranial base region and an inferior deformation of the anterior cranial base, predominantly at the frontonasomaxillary suture (Fig. $2 \mathrm{~F})$. The 11-year-old comparison indicated some compression of the posterior cranial base in the horizontal plane (Fig. 2G). Although the mid-cranial region showed some upward expansion, an inferior deformation of the anterior cranial base, predominantly localized at the frontonasomaxillary suture, was the dominant feature for this age group (Fig. 2G).

Graphical displays of FEM size-change values for the Class I vs. Class III geometries at each age group comparison are provided in Fig. 3. For the 5year-old comparison, the posterior cranial base had a high gradient of compression along the anteroposterior axishighest in the region of Bolton point (51\%, Table 5), with compression decreasing between basion and articulare (Fig. $3 \mathrm{~A})$. In contrast, the body of the sphenoid and the frontonasomaxillary regions exhibited an increase in local size, whereas the intervening region had values around the 1.0 level, indicating isometry in these regions (Table 5, Fig. $3 A)$. The 6-year-old comparison showed compression in the posterior cranial base (Bolton point, $61 \%$, Table 5), but a gradient in the body of the sphenoid and anterior cranial
$2 \mathrm{C})$. While the mid-cranial base region displayed some upward expansion, the anterior cranial base demonstrated deformation of the anterior cranial base was also evident (Fig. $2 \mathrm{~A})$. For the 6-year-old comparison, the total spline indicated vertical and horizontal compression of the posterior cranial base. Although some expansion was evident in the midcranial region, the anterior-most region of the cranial base demonstrated a most marked upward and forward deformation for this age comparison (Fig. 2B). The posterior cranial base displayed horizontal compression with vertical stretching at basion for the 7-year-old comparison as well (Fig 

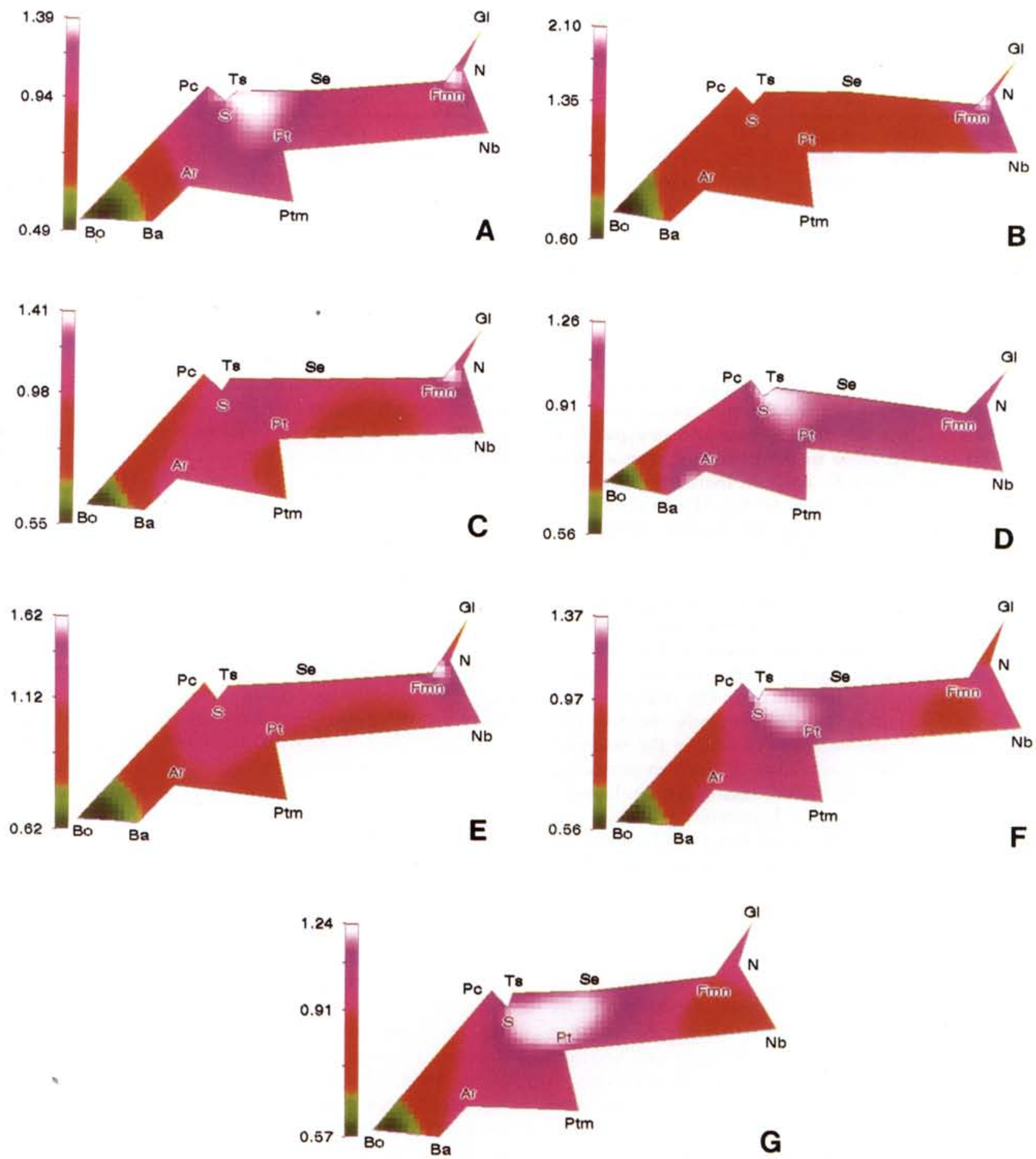

Figure 3. FEM graphical displays for each of the seven age group comparisons (5-11 years of age represented by A-G, respectively). Local decreases in size occur in the areas of Bo and Ba for all comparisons (A-G), with local increases in size in the area of the sphenoid, particularly at ages $5(\mathrm{~A}), 8(\mathrm{D}), 10(\mathrm{~F})$, and $11(\mathrm{G})$ years. Local increases in size also occur consistently at Fmn (A-G).

base was not evident (Fig. 3B). In contrast, there was a minor, relative increase in the region of the sphenoidal air sinus, but the frontonasal region showed a strong positive expansion with its epicenter located at the frontonasomaxillary suture $(90 \%$, Table 5$)$. In the 7 -year-old comparison, negative allometry was evident in the posterior cranial base (Bolton point $=45 \%$, Table 5, Fig. 3C). A relative increase in the region of the sphenoidal air sinus and the anterior region showed positive allometry (36\%, frontonasomaxillary suture, Table 5), while some localized size decrease was evident in the intervening areas. A decrease in local size was apparent in the posterior cranial base ( $40 \%$, Bolton point, Table 5$)$ which quickly diminished by the dorsum sellae, as seen for the 8-year-old comparison 
Table 5. Size-change values at each anatomical landmark determined with the FEM analysis of Class I and Class III cranial base morphologies between 5 and 11 years of age

\begin{tabular}{|c|c|c|c|c|c|c|c|c|c|c|c|c|c|}
\hline Age & Bo & $\mathrm{Ba}$ & Pc & $S$ & Ts & Se & Fmn & $\mathrm{N}$ & Gl & $\mathrm{Nb}$ & $\mathrm{Ptm}$ & $\mathrm{Pt}$ & $\mathrm{Ar}$ \\
\hline 05 & 0.492 & 0.654 & 1.227 & 1.247 & 1.314 & 1.139 & 1.260 & 1.246 & 1.071 & 1.057 & 1.061 & 1.170 & 0.945 \\
\hline 06 & 0.605 & 0.884 & 0.892 & 1.076 & 1.075 & 1.083 & 1.898 & 1.492 & 1.142 & 1.307 & 0.977 & 0.990 & 0.985 \\
\hline 07 & 0.555 & 0.803 & 0.959 & 1.097 & 1.082 & 1.011 & 1.357 & 1.265 & 1.019 & 1.045 & 0.936 & 0.961 & 0.995 \\
\hline 08 & 0.592 & 0.940 & 1.146 & 1.230 & 1.232 & 1.157 & 1.092 & 1.101 & 1.041 & 1.027 & 1.064 & 1.075 & 1.070 \\
\hline 09 & 0.648 & 0.749 & 1.065 & 1.129 & 1.136 & 1.170 & 1.543 & 1.395 & 1.019 & 1.198 & 1.010 & 1.052 & 0.978 \\
\hline 10 & 0.578 & 0.767 & 1.117 & 1.306 & 1.339 & 1.122 & 1.050 & 1.013 & 0.737 & 0.941 & 1.012 & 1.127 & 0.957 \\
\hline 11 & 0.606 & 0.791 & 1.063 & 1.170 & 1.101 & 1.136 & 1.254 & 1.358 & 1.253 & 0.991 & 0.944 & 1.082 & 0.907 \\
\hline
\end{tabular}

(Fig. 3D). In contrast, there was an increase in local size in the body of the sphenoid, but the anterior cranial base was more isometric (Fig. 3D). The 9-year-old comparison showed local size decrease in the posterior cranial base ( $35 \%$, Bolton point, Table 5), with an increasing gradient through to the body of the sphenoid (Fig. 5E). In contrast to a relative increase in the sphenoid, the anterior cranial base showed an even greater size increase, with its epicenter located at the frontonasomaxillary suture $(54 \%$, Table 5$)$. A decrease in size occurred in the posterior cranial base for the 10 -year-old comparison ( $42 \%$, Bolton point, Table 5), with an increasing gradient through to the sphenoid (Fig. 3F). The anterior cranial base was more isometric but also showed some slight decreases in local size in the region of the frontonasomaxillary suture (Fig. 3F). Similarly, the posterior cranial base showed local decreases in size for the posterior cranial base $(40 \%$, Bolton point, Table 5$)$, with an increasing gradient through to the sphenoidal region for the 11-yearold comparison (Table 5, Fig. 3G). In contrast, increased size occurred in the body of the sphenoid, but a relative decrease in size was seen in the area of the frontonasomaxillary suture (Fig. 3G).

\section{Discussion}

Although longitudinal samples may be better than crosssectional samples with the same number of radiographs for establishing growth patterns, serial cephalographs were not available for this study, which depends upon age- and sexmatched groups. Similarly, although Class III malocclusion can be defined in different ways-for example, on the basis of cephalometric analysis (e.g., Enlow et al., 1969), Class III incisor relationship (Battagel, 1994), or Class III molar relationship (Guyer et al., 1986) - only the latter definition was adopted in this particular study. Indeed, functional contributions often are an important complicating factor in Class III malocclusion, and such heterogeneity may account for some of the difficulties encountered in the investigation of Class III malocclusion (Jacobson et al., 1974). Nevertheless, a random nature of selection is a fundamentally important assumption in the analysis of variance (Sokal and Rohlf, 1981 ), and we complied with this principle despite the limited size of our cross-sectional sample.

The importance of cranial base length to the contribution of midfacial retrognathia and Class III malocclusion remains unclear due to contradictory results from cephalometric studies. Various investigators have reported that cranial base length is smaller in Class III subjects compared with their Class I counterparts (Sanborn, 1955; Hopkin et al., 1968; Kerr and Adams, 1988), while others show only minor differences (Battagel, 1993, 1994) or none at all (Anderson and Popovich, 1983; Williams and Anderson, 1986). Further, Guyer et al. (1986) reported that S-N is larger in length for Class III subjects between ages 5 and 7 . Results from the cephalometric analysis in this study indicate only slight differences in anterior cranial base length, with the Class I sample showing a greater length between 8 and 9 years of age. This concurs generally with Battagel's $(1993,1994)$ findings, where sella-nasion length was marginally greater in Class I subjects. On the one hand, it would seem that anterior cranial base length may not play an important role in the etiology of Class III malocclusion, due to the conflicting nature of the data reported in the literature. However, nasion may be quite variable in its position during growth and thus may contribute to the contradictory findings (Kerr, 1978; Lestrel et al., 1993).

The posterior cranial base, represented by Pc-Bo length in this study, was consistently and significantly shorter in Class III subjects at all ages. However, S-Ba length did not differ significantly between occlusal groups. There is ample evidence that increases in S-Ba length occur due to growth activity in the spheno-occipital synchondrosis, and that this distance increases slowly until early adulthood (Melsen, 1972, 1974; Ohtsuki et al., 1982). In fact, resorptive remodeling of the posterior cranial base probably continues in the area of the foramen magnum even after fusion of the spheno-occipital synchondrosis, which could contribute to perceived growth changes (Hoyte, 1975, 1991). Therefore, differences in growth remodeling of the clivus and foramen magnum between Class I and Class III groups probably contribute to the differences in posterior cranial base length seen in this study. Head posture may also play a role in positioning of the foramen magnum, thus augmenting Pc-Bo length (Solow and Tallgren, 1970; Cole, 1988). Alternately, cranial base angulation is considered to occur through the spheno-occipital synchondrosis (Bjork, 1955). It would seem that the Pc-Bo length would be more affected by rotation at this synchondrosis compared with S-Ba length. 
Cranial base angle, in addition to the movement of the mandible and maxilla with respect to the cranium and remodeling along the facial profile between nasion and menton, has been hypothesized as a major factor determining the degree of facial prognathism (Scott, 1958, 1967). Although this hypothesis has been supported in numerous studies (Hopkin et al., 1968; Guyer et al., 1986; Ellis and McNamara, 1984; Williams and Andersen, 1986; Kerr and Adams, 1988; Battagel, 1993, 1994; Sato, 1994), others disagree (Anderson and Popovich, 1983). Results from this study concur with these earlier findings and indicate that the saddle angle (NSBa) as well as the two other cranial base angles (NSAr and NPcBo) show differences between the Class I and Class III configurations, with more acute angles in the Class III morphology. Although Anderson and Popovich (1983) could find no correlation between cranial base angle and Class III occlusion, it would seem that this configuration is strongly influenced by acute cranial base angles. In addition to the more acute cranial base angles, Class III subjects displayed a more obtuse frontonasal angle (GINNb), presumably associated with a flatter midfacial profile.

A confounding problem in cephalometric analyses is that geometric relationships are not corrected for size (Battagel, 1994). Therefore, a larger individual may display a greater absolute length compared with a smaller subject, when in fact the value may be smaller if it is normalized for size. Procrustes analysis avoids this problem, since geometries are scaled to equivalent sizes. Results from the Procrustes analysis indicated that the overall cranial base configuration differed between groups at all ages. This finding was corroborated by the multivariate analysis which indicated an overall difference between Class I and Class III configurations at each age interval. These results support Dietrich's (1970) hypothesis that a Class III configuration is due, in part, to positional, i.e., shape, changes in the cranial base. Therefore, one would predict differences in regional morphology and growth potentials within the cranial base of Class III individuals compared with Class I subjects.

Results from the graphical analysis indicated that large spatial-scale deformations affected the posterior cranial base, while localized shearing was more apparent in the region of sella turcica and the frontonasal suture, as indicated by the thin-plate spline analysis. Similarly, decreases in local sizes occurred in the posterior cranial base, while large increases in local size were seen in the area of sella turcica and the frontonasal region. These results suggest that the posterior cranial base is displaced anteriorly relative to the anterior cranial base in Class III craniofacial configurations. This would have the effect of decreasing the total length of the cranial base and simultaneously cause an acute cranial base angle, again supporting the hypothesis that abnormal cranial base shape contributes to the etiology of a Class III malocclusion.

The shape of the cranial base appears to be established during fetal development (Ford, 1956; Diewert, 1983; Burdi et al., 1988), and it remains relatively stable during postnatal growth (Lewis and Roche, 1977; Lestrel and Roche, 1986). A prominent feature of this early growth is a progressive flattening of the cranial base during late prenatal develop- ment (Ford, 1956; Burdi, 1969; Diewert, 1983, 1985). Although some reports indicate that a closing of the cranial base angle occurs postnatally (George, 1978; Lang, 1983), morphological instability of nasion casts some doubt on these results (Kerr, 1978). Therefore, the Class III morphology may be established very early in development, possibly prenatally. As well, the Class III cranial base may arise due not to an increased cranial base flexion, but rather to deficient orthocephalization, or failure of the cranial base to flatten antero-posteriorly.

Cephalometric analysis remains the foundation for the clinical diagnosis of Class III malocclusion. However, while some authors have reported the existence of definitive cephalometric variables which can characterize a Class III malocclusion, e.g., cranial base angle (Sato, 1994), others conclude that no single cephalometric measurement is indicative of a Class III potential (Williams and Andersen, 1986). Indeed, Battagel (1994) considers the search for cephalometric parameters indicative of growth potential in Class III malocclusion to be somewhat unproductive. Therefore, this study utilized newer morphometric procedures, including Procrustes, thin-plate spline, and FEM analyses. As a result of these procedures, geometric configurations of anatomical landmarks can be scaled to equivalent areas, thus avoiding the problems introduced by differences in cranial base size. As well, the thin-plate spline and FEM graphical analyses avoid registration on any individual node, thus obviating misleading conclusions due to relative changes in position for any landmark used as a register. The relative usefulness of individual morphometric procedures is an area of intensive debate (Rohlf and Marcus, 1993). For example, valid arguments have been presented indicating that homologous point-based methods depend upon the landmarks selected for analysis as well as on the interpolation function used (Read and Lestrel, 1986; Bookstein, 1991; Richtsmeier et al., 1992). However, it would appear that each technique has relative merits and can provide useful information. Ultimately, any morphometric technique provides simply a description which can be used to hypothesize a mechanism. The biological mechanism suggested here, i.e., that Class III malocclusion results from deficient orthocephalization, remains to be tested experimentally.

\section{Acknowledgments}

Mr. John Deptuch provided technical assistance. This research is supported by MRC-10269 (SL) and HSURC (GDS).

\section{References}

Anderson D, Popovich F (1983). Relation of cranial base flexure to cranial form and madibular position. Am J Phys Anthropol 61:181-188.

Battagel JM (1993). The aetiology of Class III malocclusion examined by tensor analysis. Br J Orthod 20:283-295.

Battagel JM (1994). Predictors of relapse in orthodonticallytreated Class III malocclusions. Br J Orthod 21:1-13.

Bjork A (1955). Cranial base development. Am J Orthod 41:198-255.

Bookstein FL (1991). Morphometric tools for landmark data: Geometry and biology. Cambridge: Cambridge University Press.

Burdi AR (1969). Cephalometric growth analysis of the human 
upper face region during the last two trimesters of gestation. Am J Anat 125:133-142.

Burdi AR, Lawton TJ, Grosslight J (1988). Prenatal pattern emergence in early human facial development. Cleft Palate J 25:8-15.

Cole SC (1988). Natural head position, posture and prognathism. Br J Orthod 15:227-239.

Dietrich UC (1970). Morphological variability of skeletal Class III relationships as revealed by cephalometric analysis. Trans Eur Orthodont Soc 131-143.

Diewert VM (1983). A morphometric analysis of craniofacial growth and changes in spatial relations during secondary palatal development in human embryos and fetuses. $\mathrm{Am} \mathrm{J}$ Anat 167:495-522.

Diewert VM (1985). Growth movements during prenatal development of human facial morphology. In: Normal and abnormal bone growth, progress in basic and clinical research. Dixon AD, Sarnat BG, editors. New York: Alan R. Liss, 187:57-66.

Ellis E, McNamara JA Jr (1984). Components of adult Class III malocclusion. J Oral Maxillofac Surg 42:295-305.

Enlow DH, Moyers RE, Hunter WS, NcNamara JA Jr (1969). A procedure for the analysis of intrinsic facial form and growth. Am J Orthod 56:6-23.

Ford EHR (1956). The growth of the foetal skull. J Anat 90:63-72.

Foster TD, Day AJ (1974). A survey of malocclusion and the need for orthodontic treatment in a Shropshire school population. Br J Orthod 1:73-78.

George SL (1978). A longitudinal and cross-sectional analysis of growth of the postnatal cranial base angle. Am J Phys Anthropol 49:171-178.

Gower JC (1975). Generalized Procrustes analysis. Psychometrika 40:33-51.

Guyer EC, Ellis EE 3rd, McNamara JA Jr, Behrents RG (1986). Components of Class III malocclusion in juveniles and adolescents. Angle Orthod 56:7-30.

Haynes S (1970). The prevalence of malocclusion in English children aged 11-12 years. Trans Eur Orthod Soc 89-98.

Hopkin GB, Houston WJ, James GA (1968). The cranial base as an aetiological factor in malocclusion. Angle Orthod 38:250-255.

Hoyte DA (1975). A critical analysis of the growth in length of the cranial base. In: Morphogenesis and malformations of the face and brain. Bergsma $D$, editor. Birth defects: Orig Art Ser 11. New York: Alan R. Liss, pp. 255-282.

Hoyte DA (1991). The cranial base in normal and abnormal skull growth. Neurosurg Clin North Am 2:515-537.

Jacobson A, Evans WG, Preston CB, Sadowsky PL (1974). Mandibular prognathism. Am J Orthod 66:140-171.

Kerr WJS (1978). A method of superimposing serial lateral cephalometric films for the purpose of comparison: A preliminary report. Br J Orthod 5:51-53.

Kerr WJ, Adams CP (1988). Cranial base and jaw relationship. Am J Phys Anthropol 77:213-220.

Lang J (1983). Clinical anatomy of the head. Berlin: Springer-Verlag.

Lele S (1993). Euclidean distance matrix analysis (EDMA): Estimation of mean form and mean difference. Math Geol 25:573-602.

Lestrel P, Roche AF (1986). Cranial base shape variation with age: A longitudinal study of shape using Fourier analysis. Hum Biol 58:527-540.

Lestrel P, Bodt A, Swindler DR (1993). Longitudinal study of cranial base shape changes in Macaca nemestrina. Am J Phys Anthropol 91:117-129.

Lewis AB, Roche AF (1977). The saddle angle: Constancy or change? Angle Orthod 47:46-54.

Lozanoff S, Diewert VM (1986). Measuring histological form change with finite element methods. Am J Anat 177:187-201.

Lozanoff S, Diewert VM (1989). A computer graphics program for measuring two and three-dimensional form change in developing craniofacial cartilages using finite elements. Comp Biomed Res 22:63-82.

Lozanoff S, Jureczek S, Feng T, Padwal R (1994). Anterior cranial base morphology in mice with midfacial retrusion. Cleft Palate Craniofac J 31:417-428.

Ma W, Lozanoff S (1996). Morphological deficiency in the prenatal anterior cranial base of midfacially retrognathic mice. I Anat (in press).

Melsen B (1972). Time and mode of closure of the sphenooccipital synchondrosis determined on human autopsy material. Acta Anat 83:112-118.

Melsen B (1974). The cranial base. Acta Odontol Scand 32:62-73.

Ohtsuki F, Mukherjee D, Lewis AB, Roche AF (1982). A factor analysis of cranial base and vault dimensions in children. Am J Phys Anthropol 58:271-279.

Read DW, Lestrel PE (1986). Comment on uses of homologouspoint measures in systematics: A reply to Bookstein et al. Syst Zool 35:241-253.

Richtsmeier JT, Cheverud JM, Lele S (1992). Advances in anthropological morphometrics. Ann Rev Anthropol 21:283-305.

Rohlf FJ (1996). Appendix II: Morphometric resources available on the Internet. In: Advances in morphometrics. Marcus LF, Corti M, Loy A, Naylor GJP, Slice DE, editors. NATO ASI Series A. New York: Life Sciences 284, pp. 553-560.

Rohlf FJ, Marcus LF (1993). A revolution in morphometrics. TREE 8:129-132.

Rohlf FJ, Slice D (1990). Extensions of the Procrustes method for the optimal superimposition of landmarks. Syst Zool 39:40-59.

Sanborn RT (1955). Differences between the facial skeletal patterns of Class III malocclusion and normal occlusion. Angle Orthod 25:208-222.

Sato S (1994). Case report: Developmental characterization of skeletal Class III malocclusion. Angle Orthod 64:105-112.

Scott JH (1958). The cranial base. Am J Phys Anthropol 16:319-348.

Scott JH (1967). Dento-facial development and growth. Oxford: Pergamon Press.

Sokal RR, Rohlf FJ (1981). Biometry. New York: W.H. Freeman Co.

Solow B, Tallgren A (1976). Head posture and craniofacial morphology. Am I Phys Anthropol 44:417-435.

Stapf WC (1948). A cephalometric roentgenographic appraisal of the facial pattern in Class III malocclusion. Angle Orthod 18:20-23.

Varjanne I, Koski K (1982). Cranial base, sagittal jaw relationship and occlusion. Proc Finn Dent Soc 78:179-183.

Williams S, Andersen CE (1986). The morphology of the potential Class III skeletal pattern in the growing child. Am J Orthod 89:302-311. 


\section{Appendix $*$}

Statistical comparisons of average geometries calculated by Generalized Orthogonal Procrustes analysis.

(1) The Procrustes sum of squares

Let $X_{1}, X_{2}, \ldots X_{n}$ be $n(K$ and $D$ ) matrices of landmark

coordinates ( $K=$ landmarks; $D=$ dimensions). Let $\bar{X}_{1}, \bar{X}_{2}, \ldots \bar{X}_{n}$ be translated and rotated matrices. Calculate the sum of square as:

$$
\begin{aligned}
\mathrm{G}_{\mathrm{s}} & =\operatorname{tr}\left[\sum_{i=1}^{n} \overline{\tilde{X}}_{i} \overline{\tilde{X}}_{i}^{T}-n \overline{\widetilde{X}} \tilde{X}^{T}\right] \\
& =\quad \sum_{i=1}^{n} \operatorname{tr} \overline{\widetilde{X}}_{i} \overline{\tilde{X}}_{i}^{T}-n \operatorname{tr} \widetilde{X} \tilde{X}^{T}
\end{aligned}
$$

(2) Compare geometries.

Let $X_{1}, X_{2}, \ldots X_{n}$ be a sample from the first population, and let $Y_{1}, Y_{2}, \ldots Y_{n}$ be a sample from the second population. Let $\overline{\tilde{Y}}, \overline{\tilde{X}}$ be mean forms of the two populations. Calculate $G_{s}(X)$, or the Procrustes sum for $X$, and $G_{s}(Y)$, the Procrustes sum for $Y$. Fit $\overline{\widetilde{Y}}$ to $\overline{\widetilde{X}}$. Calculate $\mathrm{X}$

$$
\begin{aligned}
& \mathrm{J} \|=\mathrm{G}_{\mathrm{s}}(\overline{\tilde{X}}, \overline{\tilde{Y}})=\operatorname{tr}\left[\left((\overline{\tilde{X}}-\tilde{Y})\left((\tilde{\tilde{X}}-\tilde{Y})^{\mathrm{T}}\right]\right.\right. \\
& \text { where } \overline{\tilde{Y}}^{*} \text { is the fitted } \overline{\tilde{Y}} \\
& =\operatorname{tr} \overline{\tilde{X}} \overline{\tilde{X}}^{T}+\overline{\tilde{Y}} \tilde{Y}^{T}-2 \operatorname{tr} Z Z^{T} \\
& \text { where } \mathrm{Z}=\text { Procrustes mean of } \overline{\tilde{X}}, \overline{\tilde{Y}}
\end{aligned}
$$

(3) Calculate $F$ value.

$$
\mathrm{F}=\frac{\mathrm{J} \|\left(\frac{n m}{n+m}\right)\left(\frac{n+m-2}{n+m}\right)}{\mathrm{G}_{\mathrm{s}}(X)+\mathrm{G}_{\mathrm{s}}(Y)}
$$

Under i.i.d. perturbations (Langron and Collins, 1985),

$$
\begin{aligned}
& \mathrm{G}_{\mathrm{s}}(X) \sim \sigma^{2} \chi_{L_{1}}^{2} \text { and } \mathrm{G}_{\mathrm{s}}(Y) \sim \sigma^{2} \chi_{L_{1}}^{2} \text { are independent. } \\
& \text { where } L_{1}=(n-1)\left(K D-\frac{1}{2} D(D+1)\right) \\
& L_{2}=(\mathrm{m}-1)\left(K D-\frac{1}{2} D(D+1)\right)
\end{aligned}
$$

Therefore,

$$
\mathrm{G}_{\mathrm{s}}(X)+\mathrm{G}_{\mathrm{s}}(Y) \sim \sigma^{2} \chi_{L_{1}+L_{2}}^{2}
$$

Under the null hypothesis,

$$
\begin{aligned}
& \mathrm{G}_{\mathrm{s}}(\overline{\tilde{X}}, \overline{\tilde{Y}})=\mathrm{J} \| \sim \varepsilon^{2} \chi_{L_{3}}^{2} \\
& \text { where } L_{3}=K D-\frac{1}{2} D(D+1) \text { and } \varepsilon^{2}=\sigma^{2}\left(\frac{1}{n}+\frac{1}{m}\right)
\end{aligned}
$$

Thus,

$$
\begin{aligned}
& \mathrm{F}=\frac{\left[\mathrm{G}_{\mathrm{s}}(\overline{\tilde{X}}, \overline{\tilde{Y}}) / L_{3}\right] \times \frac{n m}{n+m}}{\mathrm{G}_{\mathrm{s}}(X)+\mathrm{G}_{\mathrm{s}}(Y) /\left(L_{1}+L_{2}\right)} \\
& \sim \mathrm{F}_{L_{L^{\prime}\left(L_{1}+L_{2}\right)}} \\
& \text { since } \mathrm{G}_{\mathrm{s}}(\overline{\tilde{X}}, \overline{\tilde{Y}}) \times\left(\frac{n m}{n+m} \times \frac{1}{\sigma^{2}}\right) \sim \chi_{L_{3}}^{2} \\
& \text { and } \frac{1}{\sigma^{2}}\left[\mathrm{G}_{\mathbf{s}}(X)+\mathrm{G}_{\mathbf{s}}(Y)\right]-\chi_{L_{1}+L_{2}}^{2}
\end{aligned}
$$

they are independent.
Langron SP, Collins AJ (1985). Perturbation theory for generalized Procrustes analysis. J R Statist Soc Br 47:277-284.

Based on a personal communication from S. Lele. However, any errors are the responsibility of the authors. 